\title{
Carnosic acid protects against pressure overload-induced cardiac remodelling by inhibiting the AKT/GSK3ß/NOX4 signalling pathway
}

\author{
YUN-JIE WEI, HAI-JUN XU, JIA-JUAN CHEN, XI YANG, JIAN XIONG, JING WANG and FEI CHENG \\ Department of Cardiology, Taihe Hospital of Shiyan, Affiliated to Hubei University of Medicine, \\ Shiyan, Hubei 442000, P.R. China
}

Received April 25, 2019; Accepted January 9, 2020

DOI: $10.3892 /$ etm.2020.9109

\begin{abstract}
Oxidative stress and apoptosis serve an important role in the development of pressure overload-induced cardiac remodelling. Carnosic acid (CA) has been found to exert antioxidant and anti-apoptotic effects. The present study investigated the underlying mechanism of CA protection and whether this effect was exerted against pressure overload-induced cardiac remodelling. Aortic banding (AB) surgery was performed to induce cardiac remodelling. Mice were randomly divided into four groups ( $n=15 /$ group): i) Sham + vehicle; ii) sham + CA; iii) $\mathrm{AB}+$ vehicle; and iv) $\mathrm{AB}+\mathrm{CA}$. After 2 days of $\mathrm{AB}, 50 \mathrm{mg} \mathrm{kg}$ CA was administered orally for 12 days. Echocardiography, histological analysis and molecular biochemistry techniques were performed to evaluate the roles of CA. CA treatment decreased cardiac hypertrophy, fibrosis, oxidative stress and apoptosis in mice challenged with pressure overload. CA also decreased the cross-sectional area of cardiomyocytes and the mRNA and protein expression levels of hypertrophic markers. Furthermore, CA treatment decreased collagen deposition, $\alpha$-smooth muscle actin expression and the mRNA and protein expression of various fibrotic markers. Additionally, $\mathrm{CA}$ reversed the AB-mediated increase in NAPDH oxidase (NOX) 2, NOX4 and 4-hydroxynonenal levels. The number of apoptotic cells was decreased following CA treatment following under conditions of pressure overload. CA also suppressed the activation of AKT and glycogen synthase kinase $3 \beta$ (GSK $3 \beta)$ in mice challenged with AB. The present results suggested that CA could inhibit pressure overload-induced cardiac hypertrophy and fibrosis by suppressing the AKT/GSK3 $\beta /$ NOX4 signalling pathway. Therefore, CA may be a promising therapy for cardiac remodelling.
\end{abstract}

Correspondence to: Dr Fei Cheng, Department of Cardiology, Taihe Hospital of Shiyan, Affiliated to Hubei University of Medicine, 32 Renmin South Road, Shiyan, Hubei 442000, P.R. China

E-mail: chengfei1029@126.com

Key words: carnosic acid, cardiac hypertrophy, cardiac fibrosis, oxidative stress, AKT

\section{Introduction}

Cardiac remodelling is a series of complex molecular and cellular mechanisms that lead to changes in cardiac structure, function and phenotype (1). The most common structural changes in pressure overload-induced cardiac remodelling are left ventricular hypertrophy and interstitial fibrosis (1). Pressure overload is a cause of cardiac remodelling (2). Pathological cardiac remodelling is associated with a series of pathophysiological changes, involving oxidative stress (3), inflammation (4), apoptosis (5) and autophagy (6). Previous studies have indicated that oxidative stress plays a vital role in the progression of cardiac remodelling $(7,8)$. NADPH oxidase (NOX) is one of the main sources of reactive oxygen species (ROS) (7) and mice overexpressing NOX4 have demonstrated an 8-fold increase in the production of ROS (8). Increased ROS not only mediates cardiomyocyte hypertrophy and apoptosis, but also inactivates nitric oxide (NO), which can induce or aggravate cardiac fibrosis (9). Therefore, the inhibition of oxidative stress may serve as a potential target for the treatment of cardiac remodelling.

Carnosic acid (CA) is a phenolic terpenoid separated from Rosmarinus officinalis that exerts multiple pharmacological effects, including antioxidative stress (10), anti-inflammation (11) and anti-tumour effects (12). A previous study has revealed that $\mathrm{CA}$ inhibits arsenic-induced hepatotoxicity by inhibiting oxidative stress (10). Furthermore, CA inhibits liver ischaemia/reperfusion injury by reducing ROS (13). A previous study has indicated that isoproterenol-induced cardiac oxidative stress activates apoptosis-associated pathways directly or via ROS and that pre-treatment with CA inhibits oxidative stress and apoptosis in mice (14). Previous studies have revealed that phosphorylated (p-) AKT and p-glycogen synthase kinase $3 \beta$ (GSK3 $\beta$ ) serve important roles in cardiac remodelling $(15,16)$. CA inhibits renal fibrosis and oxidative stress by suppressing AKT-mediated NOX4 (17). However, the effects of CA on pressure overload-induced cardiac remodelling and the molecular mechanisms underlying this remain unclear.

According to previous studies $(15,16,17)$, CA improves cardiac remodelling induced by pressure overload via the AKT/GSK3 $\beta /$ NOX4 signalling pathway. Therefore, the present study investigated the potential protective role of $\mathrm{CA}$ in cardiac remodelling. 


\section{Materials and methods}

Chemicals and reagents. CA (Fig. 1A; $>98 \%$ purity, as detected by high-performance liquid chromatography) was acquired from Shanghai Winherb Medical S\&T Development Co., Ltd., (cat. no. 3650--09-7). Total Superoxide Dismutase (SOD) Assay Kit with WST-8 (cat. no. S0101), Lipid Peroxidation malondialdehyde (MDA; cat. no. S0131) Assay kit and NADP+/NADPH Assay kit with WST-8 (cat. no. S0179) were purchased from Beyotime Institute of Biotechnology. The following antibodies were purchased from Abcam: NOX2 (1:1,000; cat. no. ab80508), NOX4 (1:1,000; cat. no. ab154244), collagen I (1:1,000; cat. no. ab34710), collagen III (1:1,000; cat. no. ab7778) and connective tissue growth factor (CTGF; 1:1,000; cat. no. ab209780). The following antibodies were purchased from Cell Signalling Technology, Inc.: Bax (1:1,000; cat. no. 2722), Bcl-2 (1:1,000; cat. no. 2870), cleaved (C-) caspase-3 (1:1,000; cat. no. 9661), p-AKT (1:1,000; cat. no. 4060), total (t)-AKT (1:1,000; cat. no. 4691), p-GSK3 $\beta$ (1:1,000; cat. no. 9323), T-GSK3 3 (1:1,000; cat. no. 9315) and GAPDH (1:1,000; cat. no. 2118). The following antibodies were obtained from Santa Cruz Biotechnology, Inc: Atrial natriuretic peptide (ANP; 1:1,000; cat. no. sc-20158), brain natriuretic peptide (BNP; 1:1,000; cat. no. sc-271185) and $\beta$-myosin heavy chain ( $\beta$-MHC; $1: 1,000$; cat. no. sc-53090). These antibodies were normalized to GAPDH expression. Secondary antibodies including IRDye 800CW Goat anti-Mouse (cat. no. 926-32210) and IRDye 800CW Goat anti-Rabbit (cat. no. 926-32211), were obtained from LI-COR Biosciences (1:10,000).

Animals and experimental design. All animal care and experiments were based on the Guidelines for the Care and Use of Laboratory Animals published by the United States National Institutes of Health (NIH Publication, revised 2011) (18) and were approved by the Animal Care and Use Committee of Wuhan University. Male C57/B6 mice (age, 8-10 weeks; weight, 23.5-27.5 g) were purchased from the Institute of Laboratory Animal Science, Chinese Academy of Medical Sciences. The mice had free access to food and water and were housed under a specific-pathogen-free environment and a controlled temperature $\left(20-25^{\circ} \mathrm{C}\right)$ and humidity $(50 \pm 5 \%)$ with a $12 \mathrm{~h} \mathrm{light/dark}$ cycle. A total of 60 animals were randomly divided into four groups: i) Vehicle + sham $(n=15)$; ii) $C A+$ sham $(n=15)$; iii) vehicle + aortic banding $(A B ; n=15)$; and iv) $A B+C A(n=15)$. Mice were subjected to $A B$ surgery to establish a model of cardiac fibrosis and surgery was performed based on previously described methods (19). Via intraperitoneal injection, in total $3 \% 80 \mathrm{mg} / \mathrm{kg}$ pentobarbital was used to anaesthetize animals. After anaesthesia, hair over the thoracic surgery area was sheared. Following local disinfection with iodine, fluoride and alcohol, mice were fixed on the operating table. An insert was made into the trachea and the skin was cut along the second and third intercostal level. The muscles and soft tissues were separated in turn, revealing the thoracic aorta. The aorta was then freed from connective tissue and a surgical suture was wrapped around the vessel. The thread was tightened against a 27 -guauge needle placed on the freed portion of the aorta. Following ligation, the needle was removed. For the sham-operated groups, after the aorta was freed, surgical thread was wound around the vessel, but no ligation was performed. The two $\mathrm{AB}$ groups received the same surgical procedure. After 2 days of $A B, 50 \mathrm{mg} / \mathrm{kg} \mathrm{CA}$ was administered orally once a day for 12 days. A period of four weeks following the $\mathrm{AB}$ operation, echocardiography and haemodynamic parameters were analysed and mice were sacrificed via cervical dislocation. The heart weight was then measured, along with tibia length.

Echocardiography measurement and invasive hemodynamic pressure-volume analysis. A MyLabTM 30CV (Esaote SpA) and a $10-\mathrm{MHz}$ linear array ultrasound transducer (Esaote $\mathrm{SpA}$ ) were used to detect cardiac function, as reported previously (20). A total of $1.5 \%$ isoflurane (21) was used to anaesthetize mice on a $37^{\circ} \mathrm{C}$ temperature-controlled warming pad. Corneal reflex, pain reflex, respiration and muscle tension were monitored in mice to ensure they were anesthetized. When the mouse was appeared calm, was in the supine position, did not feel pain, did not exhibit righting reflex and had relaxed limbs the mouse was determined to have entered the anesthesia maintenance period. The following parameters were measured: Ejection fraction (EF), left ventricle end-diastolic diameter (LVEDd), left ventricle end-systolic diameter (LVESd) and the percentage fraction of shortening, all of which were calculated as described previously (21). The present study first measured the LVEDd and LVESd. The LVFS was calculated as [(LVEDd-LVESd)/LVEDd] ${ }^{*} 100 \%$, and LVEF was calculated based on the Teichhotz formula (22).

A 1.4-F Millar microtip pressure transducer was used for invasive haemodynamic pressure-volume detection. Mice were then anesthetised with $2 \%$ isoflurane on a $37^{\circ} \mathrm{C}$ temperature-controlled warming pad. A pressure-volume conductance system was used to detect heart rate and the derivative of pressure over time (dp/dt). PVAN data analysis software (Millar) was used to analyse the end-systolic pressure (ESP), end-diastolic pressure (EDP), the maximal rate of pressure development (dp/dtmax) and the minimal rate of pressure decay (dp/dtmin).

Histological analysis. After 12 days of treatment with CA, extracted hearts were rapidly soaked in $10 \% \mathrm{KCl}$ solution to keep the heart at diastole. Hearts were then fixed with $4 \%$ formalin for 2-3 days at room temperature, dehydrated and embedded in paraffin, then cut to 4-5 $\mu \mathrm{m}$ sections. To assess the cross-sectional area of cardiomyocytes, haematoxylin and eosin (HE) staining was performed under room temperature for $1 \mathrm{~h}$. To evaluate collagen deposition, picrosirius red (PSR) staining and Masson staining were performed on the cardiac sections under room temperature for $3 \mathrm{~h}$ (23). A light microscope was used to visualize the cardiac sections at magnifications of $\mathrm{x} 400$ and $\mathrm{x} 200$. The cross-sectional area of the cardiomyocytes and the degree of collagen deposition were analysed using the Image-Pro Plus v6.0 quantitative digital image analysis system (Media Cybernetics, Inc.). $\geq 100$ myocardial cells in each group were analysed (24).

Immunohistochemistry staining. Immunohistochemistry for 4-hydroxynonenal (4-HNE) and $\alpha$-smooth muscle actin $(\alpha-$ SMA) was conducted to evaluate the level of oxidative stress and the activation of myofibroblasts, respectively. The hearts of each group were fixed with $4 \%$ neutral formaldehyde solution for 2-3 days under room temperature and then 
Table I. Primer sequences.

\begin{tabular}{|c|c|c|}
\hline Gene & Species & Sequences $\left(5^{\prime}-3^{\prime}\right)$ \\
\hline ANP & Mouse & $\begin{array}{l}\text { F: ACCTGCTAGACCACCTGGAG } \\
\text { R: CCTTGGCTGTTATCTTCGGTACCGG }\end{array}$ \\
\hline $\mathrm{BNP}$ & Mouse & $\begin{array}{l}\text { F: GAGGTCACTCCTATCCTCTGG } \\
\text { R: GCCATTTCCTCCGACTTTTCTC }\end{array}$ \\
\hline$\beta-\mathrm{MHC}$ & Mouse & $\begin{array}{l}\text { F: CCGAGTCCCAGGTCAACAA } \\
\text { R: CTTCACGGGCACCCTTGGA }\end{array}$ \\
\hline Collagen I & Mouse & $\begin{array}{l}\text { F: TGGTACATCAGCCCGAAC } \\
\text { R: GTCAGCTGGATAGCGACA }\end{array}$ \\
\hline Collagen III & Mouse & $\begin{array}{l}\text { F: GTCAGCTGGATAGCGACA } \\
\text { R: GAAGCACAGGAGCAGGTGTAGA }\end{array}$ \\
\hline CTGF & Mouse & $\begin{array}{l}\text { F: GACATGCCGCCTGGAGAAAC } \\
\text { R: AGCCCAGGATGCCCTTTAGT }\end{array}$ \\
\hline NOX2 & Mouse & $\begin{array}{l}\text { F: GACCATTGCAAGTGAACACCC } \\
\text { R: AAATGAAGTGGACTCCACGCG }\end{array}$ \\
\hline NOX4 & Mouse & $\begin{array}{l}\text { F: GACCATTGCAAGTGAACACCC } \\
\text { R: AAATGAAGTGGACTCCACGCG }\end{array}$ \\
\hline GAPDH & Mouse & $\begin{array}{l}\text { F: TCATCAACGGGAAGCCCATC } \\
\text { R: CTCGTGGTTCACACCCATCA }\end{array}$ \\
\hline
\end{tabular}

ANP, atrial natriuretic peptide; BNP, brain natriuretic peptide; $\beta$-MHC, $\beta$-myosin heavy chain; CTGF, connective tissue growth factor; NOX2, NAPDH oxidase 2; NOX4, NAPDH oxidase 4; F, forward; R, reverse.

dewaxed to hydrate. Antigen repair was performed using the citric acid method (Citrate Antigen Retrieval Solution; P0081; Beyotime Institute of Biotechnology) according to the manufacturer's protocol. The sections blocked with $8 \%$ goat serum for $30 \mathrm{~min}$ at $37^{\circ} \mathrm{C}$. Cardiac sections $(4-5 \mu \mathrm{m})$ were incubated with 4-HNE (1:100; cat. no. ab46545; Abcam) and $\alpha$-SMA (1:100; cat. no. ab5694; Abcam) antibodies at $37^{\circ} \mathrm{C}$ for $2 \mathrm{~h}$. After rinsing, EnVisionTM+/HRP (K400011-2, Dako; Agilent Technologies, Inc.) was added to cardiac sections for $1 \mathrm{~h}$ at $37^{\circ} \mathrm{C}$ and samples were processed using a peroxide-based substrate diaminobenzidine kit (Gene Tech Biotechnology Co., Ltd.) and haematoxylin for staining nuclei for $1 \mathrm{sec}$ at room temperature. Neutral resin adhesive was used for sealing. Finally, heart sections were photographed using a light microscope (magnification, x200 and x400) as previously described (23).

Determination of oxidative stress. To assess the SOD1 concentration, NADPH oxidase and the lipid peroxidation product MDA of the left ventricle were assessed. Commercial kits purchased from Beyotime Institute of Biotechnology were used to determine oxidative stress and performance based on the manufacturer's protocol.

Western blotting and reverse transcription-quantitative PCR $(R T-q P C R)$. Protein extraction and SDS-PAGE of the cardiac tissues were performed according to previous study (23). Left ventricular tissues were homogenized in Radio Immunoprecipitation Assay lysis buffer (cat. no. P0013C;
Beyotime Institute of Biotechnology). The concentration of the protein samples was detected using a BCA Protein Assay kit (Thermo Fisher Scientific, Inc.). Sample buffer and water were added to homogenate the protein samples. Equal quantities of protein were placed into $10 \%$ SDS-PAGE gel for electrophoresis. The target protein was then transferred to PVDF membranes using membrane transfer apparatus and blocked in Tri-buffered saline containing 5\% skim milk powder for $60 \mathrm{~min}$ at room temperature, and incubated with primary antibodies at $4^{\circ} \mathrm{C}$ overnight. Subsequently, the membranes were incubated with IRDye $800 \mathrm{CW}$ conjugated goat anti-rabbit IgG (cat. no. P/N 925-32211; 1:1,250; LI-COR Biosciences) for $1 \mathrm{~h}$ at room temperature. The PVDF membranes were scanned and analysed using an Odyssey Infrared Imaging System (LI-COR Biosciences). Each sample was normalized to GAPDH.

For reverse transcription-quantitative PCR analysis, TRIzol reagent (Invitrogen; Thermo Fisher Scientific, Inc.) was used to extract total mRNA from left ventricular tissues at room temperature. A cDNA synthesis kit (cat. no. 04896866001; Roche Applied Science) and oligo (dT) primers were subsequently used to synthesize the first strand cDNA. RT and qPCR were performed as reported previously (25), $20 \mu 1$ reactions according to the standard protocol of the manufacturer and ran the cycle $95^{\circ} \mathrm{C}$ for $5 \mathrm{~min}, 45$ cycles (of $95^{\circ} \mathrm{C}$ for $10 \mathrm{sec}, 60^{\circ} \mathrm{C}$ for $10 \mathrm{sec}$ and $72^{\circ} \mathrm{C}$ for $10 \mathrm{sec}$ ), $95^{\circ} \mathrm{C}$ for $5 \mathrm{sec}, 60^{\circ} \mathrm{C}$ for $1 \mathrm{~min}$, $97^{\circ} \mathrm{C}$ for $0.11 \mathrm{sec}$ and $40^{\circ} \mathrm{C}$ for $10 \mathrm{~min}$. The mRNA expression level normalized against GAPDH mRNA levels. The primers used for qPCR are presented in Table I. 
A<smiles>CC(C)c1cc2c(c(O)c1O)[C@@]1(O)CCCC(C)(C)[C@@]1(C)CC2</smiles>

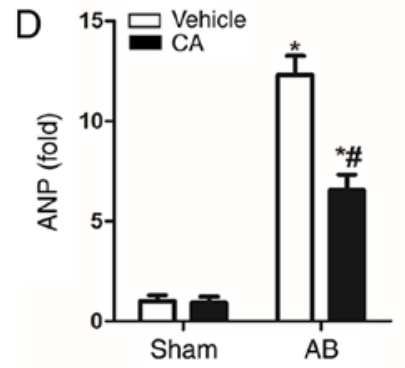

B
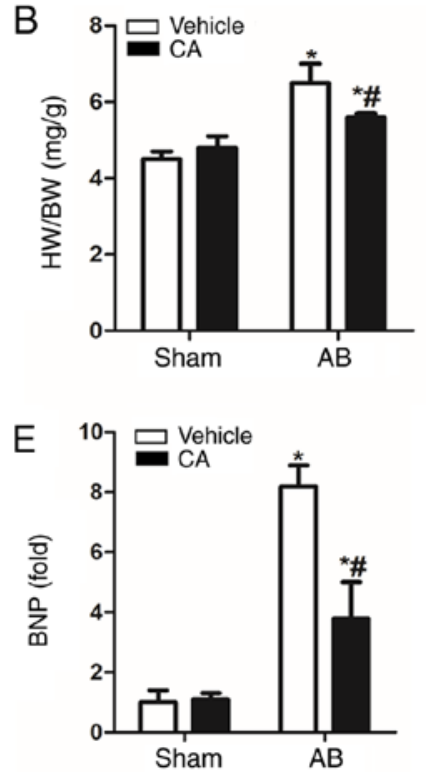

C

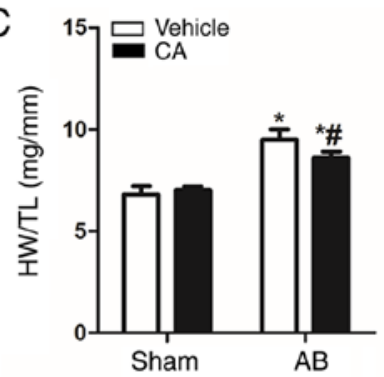

F

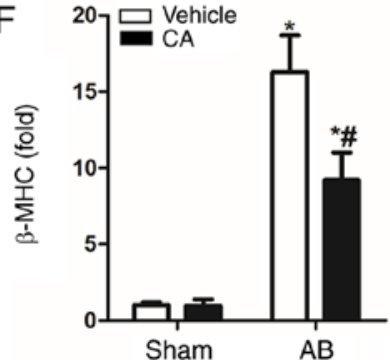

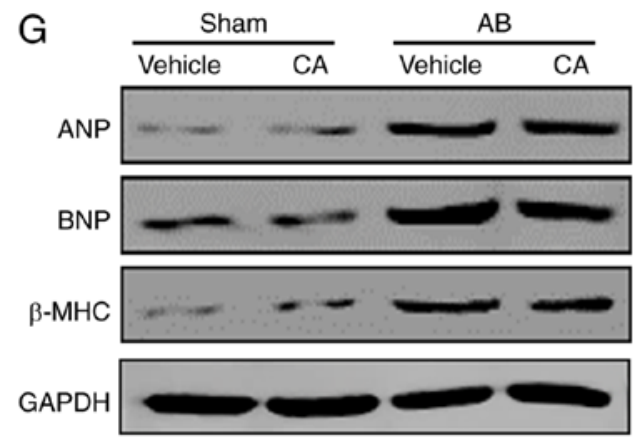

$\mathrm{H}$
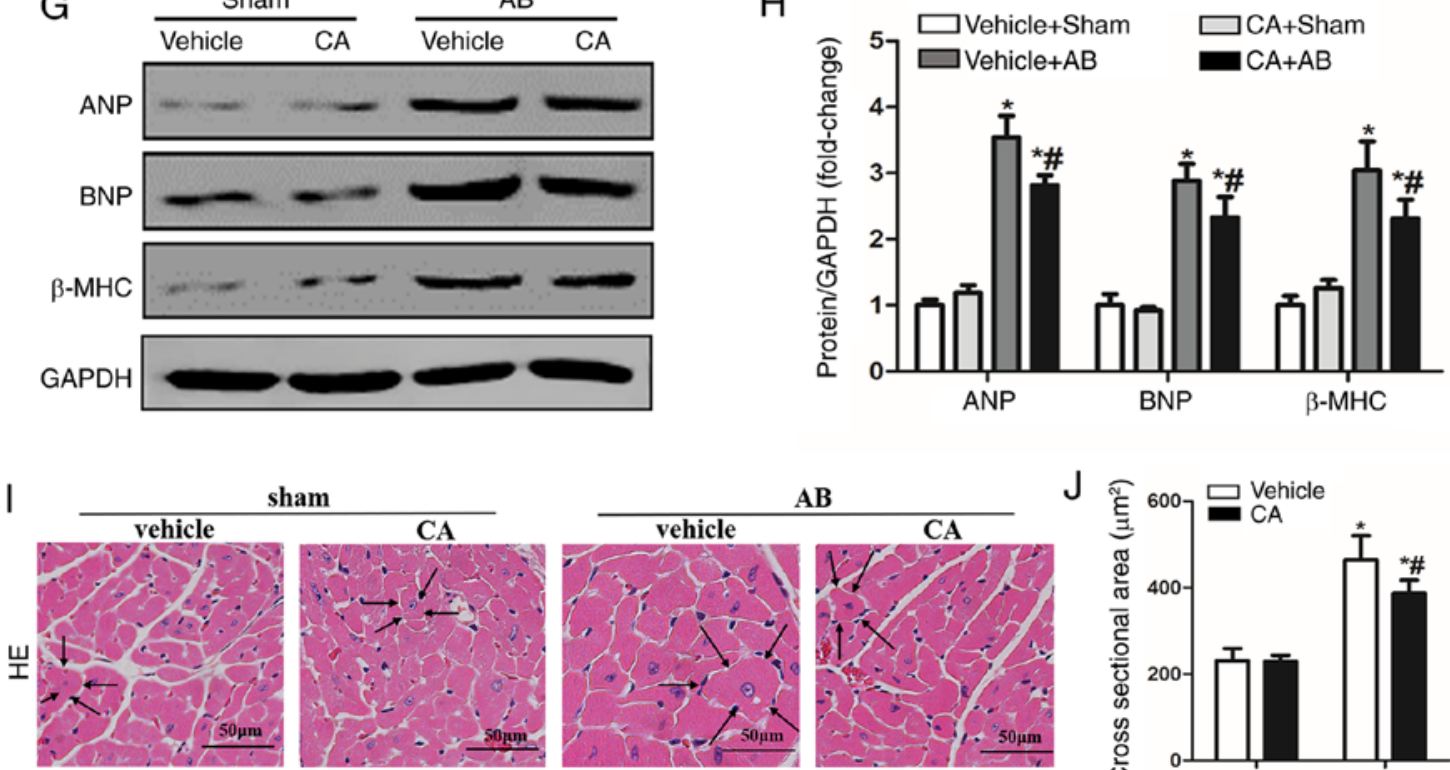

AB
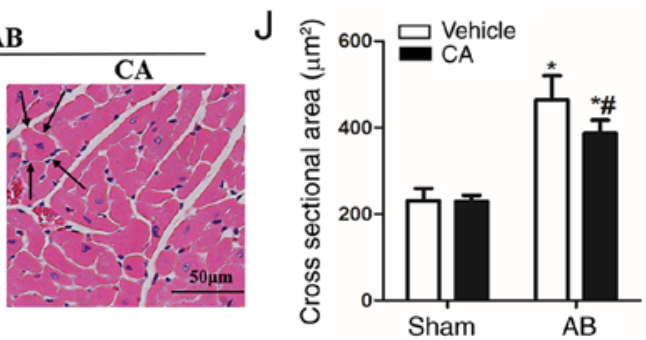

Figure 1. CA alleviated pressure overload-induced cardiac hypertrophy in mice. (A) Chemical structure of CA. Statistical results of (B) HW/BW and (C) HW/ TL $(n=15)$. mRNA expressions of (D) ANP, (E) BNP and (F) $\beta$-MHC are presented in each group. (G) Protein levels of ANP, BNP and $\beta$-MHC, and (H) quantitative analysis is presented for each group. (I) Haematoxylin and eosin staining (the surrounding arrows indicated the size of each cardiomyocyte), and (J) statistical data of the cardiomyocyte cross-sectional areas of each group $\left(\geq 100\right.$ cells/heart). Scale bar, $50 \mu \mathrm{m} .{ }^{~} \mathrm{P}<0.05$ vs. the vehicle + sham group. ${ }^{~} \mathrm{P}<0.05$ vs. the vehicle $+\mathrm{AB}$ group. $\mathrm{HW} / \mathrm{BW}$, heart weight/body weight; ANP, atrial natriuretic peptide; BNP, B-type natriuretic peptide; $\beta$-MHC, $\beta$-myosin heavy chain; CA, carnosic acid; AB, aortic banding; HE, haematoxylin and eosin.

TUNEL Staining. An apoptosis detection kit was used for staining cardiac tissue slides based on the manufacturer's protocol. The hearts of each group were fixed with $4 \%$ neutral formaldehyde solution for 2-3 days under room temperature and then dewaxed to hydrate. After xylene dewaxing and ethanol dehydration, cardiac tissue sections were incubated in $20 \mu \mathrm{g} / \mathrm{ml}$ proteinase $\mathrm{K}$ for $20 \mathrm{~min}$ and fluorescein-labelled dUTP for $1 \mathrm{~h}$ at $37^{\circ} \mathrm{C}$. DAPI Hematoxylin was used to stain cardiomyocyte nuclei for 1 second under room temperature. Neutral resin adhesive used for sealing. Fluorescence microscopy (200X) was used to view the slides and $\geq 100$ myocardial cells in each group were analysed. Image-Pro Plus 6.0 was used to calculate the results (24).
Statistical analysis. Each experiment was repeated three times. Data are presented as mean \pm SEM, and were analysed using SPSS v16.0 software (SPSS, Inc.). Two-way ANOVA followed by a Tukey post hoc test was used for data analysis. $\mathrm{P}<0.05$ was considered to indicate a statistically significant difference.

\section{Results}

CA alleviates pressure overload-induced cardiac hypertrophy in mice. To evaluate the protective role of $\mathrm{CA}$ in pressure overload-induced cardiac hypertrophy, the present study established a mouse model of cardiac hypertrophy with or without $\mathrm{CA}$ for 12 days. The vehicle $+\mathrm{AB}$ group demonstrated 
A

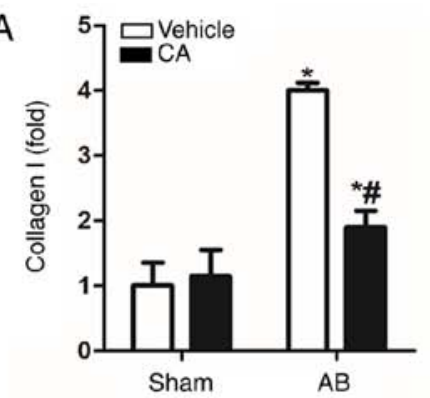

B

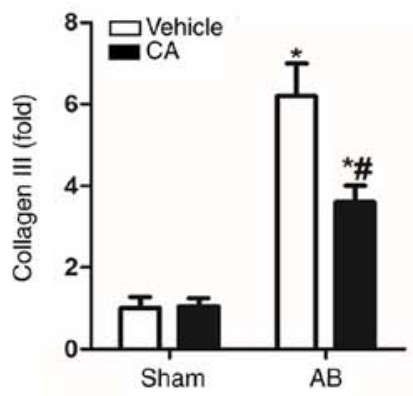

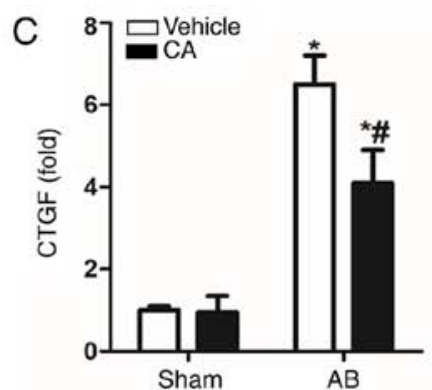

D

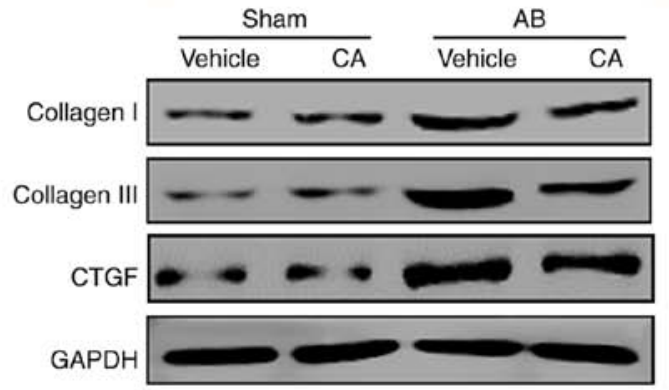

E

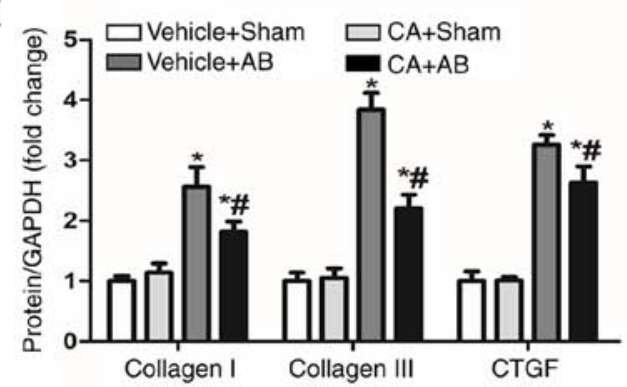

F

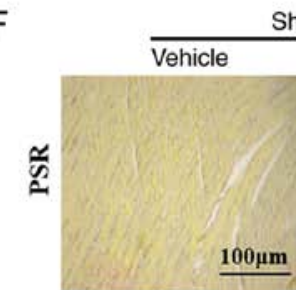

Sham

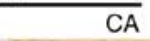

$C A$

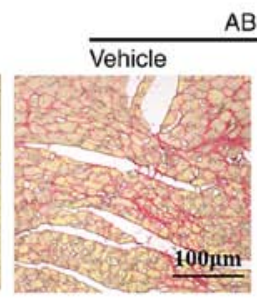

$\mathrm{AB}$

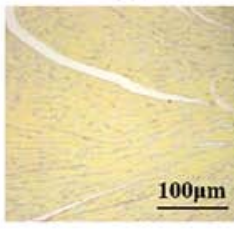

H
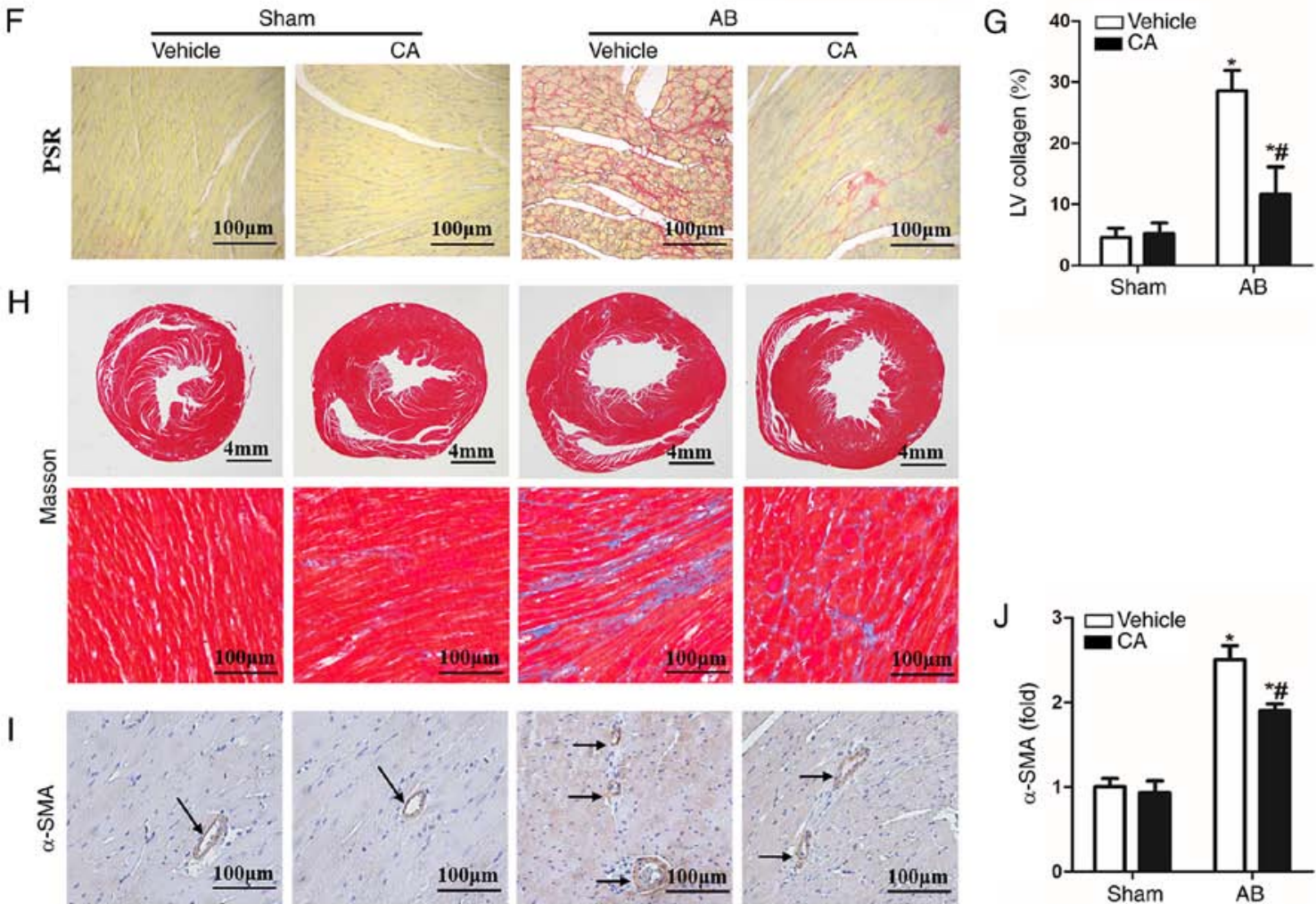

Figure 2. CA attenuated pressure overload-induced cardiac fibrosis in mice. mRNA levels of (A) collagen I, (B) collagen III and (C) CTGF are presented in each group ( $\mathrm{n}=15$ ). (D) Protein expression of collagen I, collagen III and CTGF and (E) quantitative analysis in each group. (F) PSR staining for cardiac fibrosis and (G) statistical data on the percentage fibrosis of interstitial fibrosis in each group. (H) Masson staining in each group. (I) Immunohistochemistry staining for $\alpha$-SMA protein (the arrows indicated the $\alpha$-SMA in blood vessel) and the $(\mathrm{J})$ quantitative analysis in each group. ${ }^{*} \mathrm{P}<0.05 \mathrm{vs}$. the vehicle + sham group. ${ }^{\#} \mathrm{P}<0.05$ vs. the vehicle + AB group. CTGF, connective tissue growth factor; PSR, picrosirius red; $\alpha$-SMA, $\alpha$-smooth muscle actin; CA, carnosic acid; AB, aortic banding.

increased heart weight/body weight (HW/BW) and HW/tibia length $(\mathrm{HW} / \mathrm{TL})$ ratios compared with the vehicle + sham and $\mathrm{CA}+$ sham groups. Treatment with $\mathrm{CA}$ in mice subjected to $\mathrm{AB}$ surgery significantly decreased cardiac hypertrophy, as indicated by decreased $\mathrm{HW} / \mathrm{BW}$ and $\mathrm{HW} / \mathrm{TL}$ ratios (Fig. 1B and C). Furthermore, hypertrophic markers including ANP, BNP and $\beta$-MHC were significantly increased in the vehicle $+\mathrm{AB}$ group compared with the vehicle + sham group but were decreased following $\mathrm{CA}$ treatment in the $\mathrm{CA}+\mathrm{AB}$ group (Fig. 1D-F). The present results also indicated that $\mathrm{CA}$ significantly decreased the protein expression of ANP, BNP and $\beta$-MHC induced by AB (Fig. $1 \mathrm{G}$ and $\mathrm{H}$ ). Furthermore, $\mathrm{HE}$ staining indicated that the enlarged cardiomyocyte area induced by pressure overload was alleviated by CA treatment (Fig. 1I and J). The present results suggested that CA alleviated pressure overload-induced cardiac hypertrophy in mice. 
A

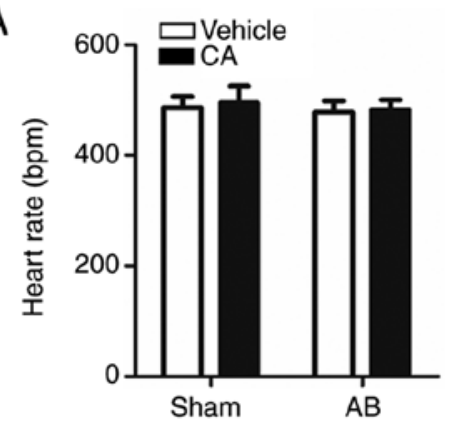

D

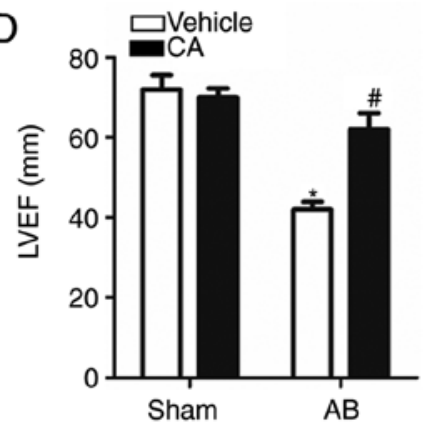

B

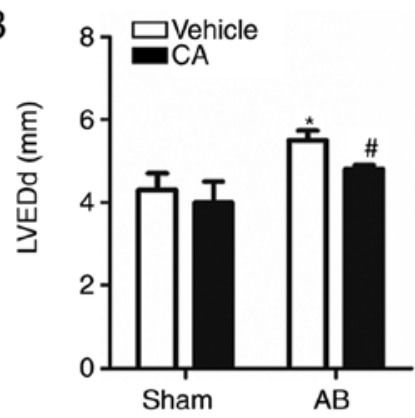

E

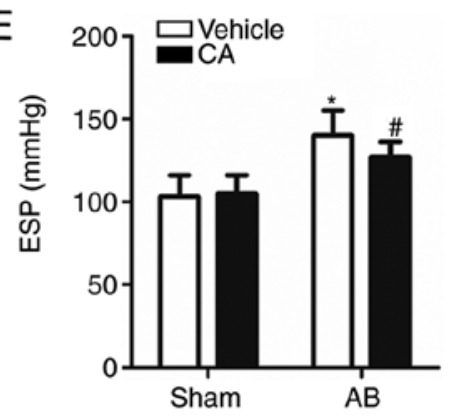

C

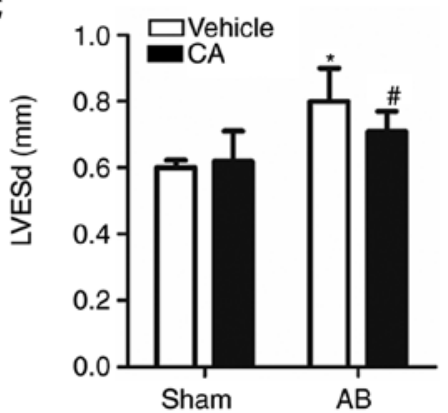

F

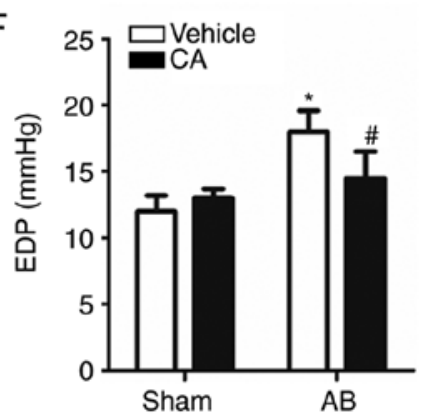

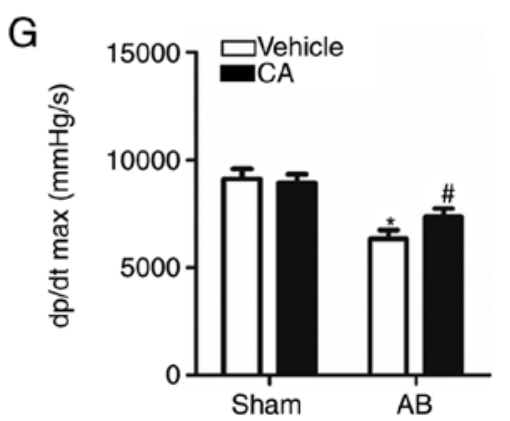

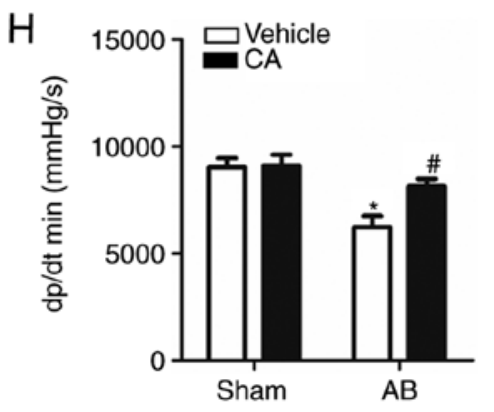

Figure 3. CA improved pressure overload-induced cardiac dysfunction in mice. (A) Heart rates of the mice in each group ( $\mathrm{n}=15)$. Echocardiographic parameters, including (B) LVEDd, (C) LVESd and (D) LVEF in each group. Haemodynamic parameters including (E) ESP, (F) EDP, (G) dp/dt max and (H) dp/dt min were presented for each group. ${ }^{*} \mathrm{P}<0.05$ vs. the vehicle + sham group. ${ }^{*} \mathrm{P}<0.05$ vs. the vehicle $+\mathrm{AB}$ group. LVEDd, left ventricle end-diastolic diameter; LVESd, left ventricle end-systolic diameter; LVEF, left ventricle ejection fraction; ESP, end-systolic pressure; EDP, end-diastolic pressure; dp/dt max, maximal rate of pressure development; $\mathrm{dp} / \mathrm{dt}$ min, minimal rate of pressure decay; $\mathrm{CA}$, carnosic acid; $\mathrm{AB}$, aortic banding.

CA attenuates pressure overload-induced cardiac fibrosis in mice. Cardiac fibrosis is a characteristic of cardiac remodelling, which ultimately leads to the conversion of cardiac hypertrophy to heart failure (2). Therefore, the present study investigated the effect of CA on cardiac fibrosis. PSR staining and Masson staining were performed to evaluate cardiac fibrosis 4 weeks after AB surgery. The results indicated enhanced mRNA (Fig. 2A-C) and protein (Fig. 2D and E) levels of fibrotic markers, including collagen I, collagen III and CTGF, which was consistent with significant perivascular and cardiac fibrosis (Fig. 2F-H), compared with the vehicle + sham and $\mathrm{CA}+$ sham groups. $\mathrm{CA}$ treatment in $\mathrm{AB}$ mice led to a significant reduction in cardiac fibrosis and the mRNA and protein expression of certain fibrotic markers. Furthermore, the expression of $\alpha$-SMA was increased in the vehicle $+\mathrm{AB}$ group and decreased in the $\mathrm{CA}+\mathrm{AB}$ group (Fig. 2I and $\mathrm{J}$ ). The present results indicated that $\mathrm{CA}$ alleviated pressure overload-induced cardiac fibrosis in mice.

CA improves pressure overload-induced cardiac dysfunction in mice. Echocardiography and pressure-volume loop measure- ments were performed to assess cardiac function in mice with or without $A B$ surgery. The result revealed no significant difference in heart rate between each group (Fig. 3A), indicating that $\mathrm{CA}$ exerted no clear effect on heart rate. It was also revealed that echocardiographic parameters, including LVEDd and LVESd, were increased (Fig. 3B and C) and the levels of LVEF were decreased in the vehicle $+\mathrm{AB}$ group compared with the vehicle + sham and CA + sham groups (Fig. 3D). The haemodynamic parameters, ESP and EDP, were elevated (Fig. 3E and F) and the $\mathrm{dp} / \mathrm{dt} \max$ and $\mathrm{dp} / \mathrm{dt} \mathrm{min}$, indicating the systolic and diastolic function respectively, were decreased in the vehicle $+\mathrm{AB}$ group compared with the vehicle + sham and $\mathrm{CA}+$ sham groups (Fig. 3G and H). The present results suggested that all the impaired parameters could be improved and harmful parameters could be restored after $\mathrm{CA}$ treatment following $\mathrm{AB}$ surgery.

CA suppresses pressure overload-induced oxidative stress in mice. Oxidative stress is involved in the pathophysiology of cardiac remodelling and a previous study has demonstrated that CA possesses strong antioxidant abilities (14). Therefore, the present study investigated whether CA treatment allevi- 

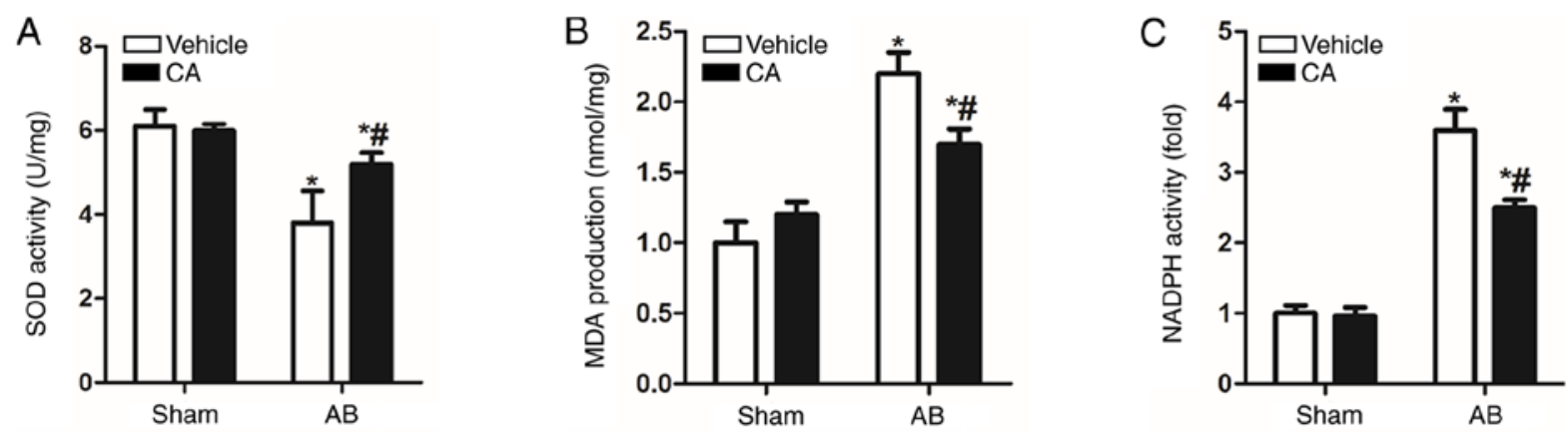

D
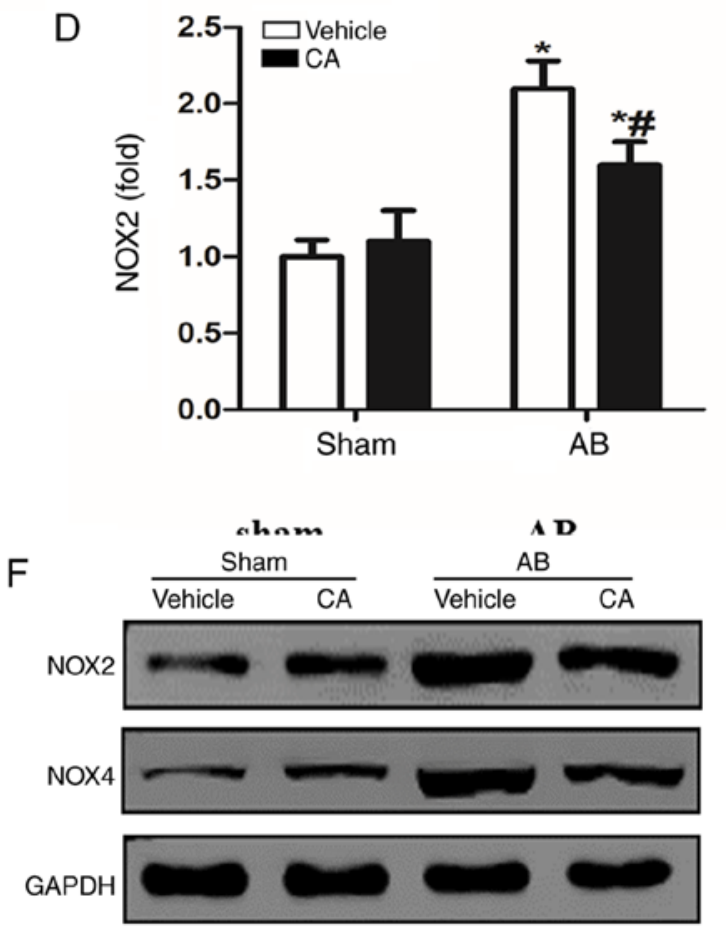

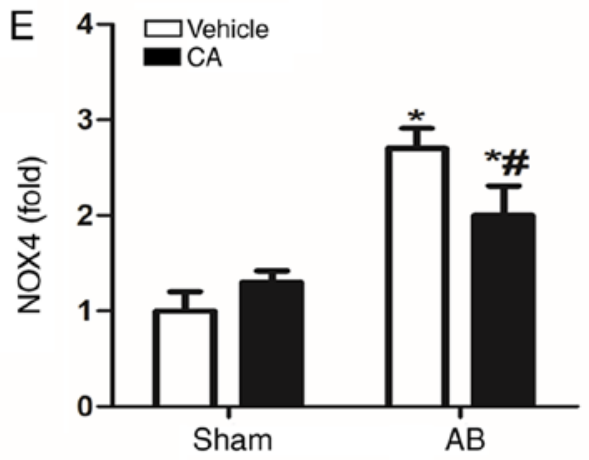

G

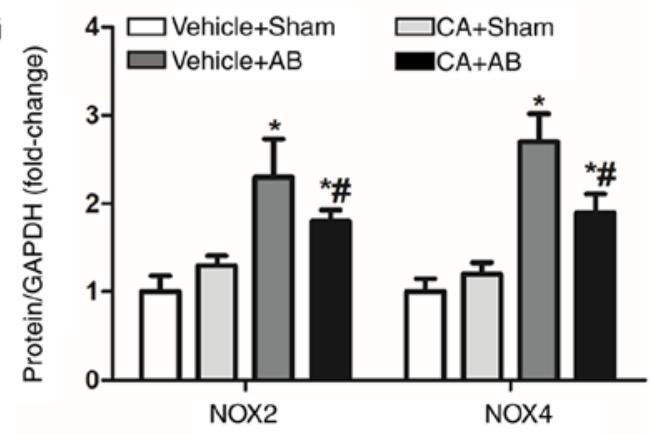

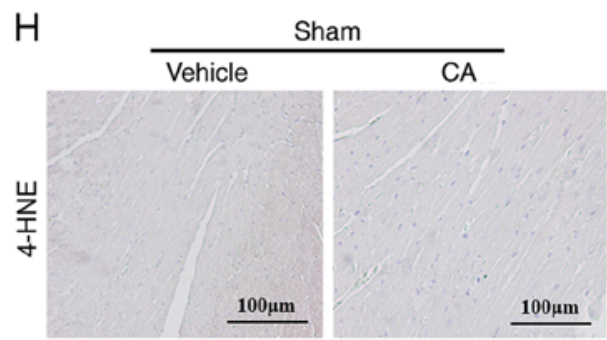
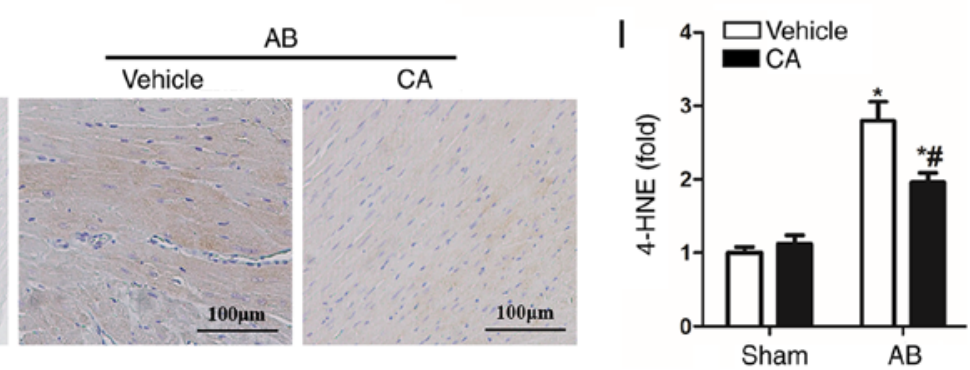

Figure 4. CA suppressed oxidative stress in mice induced by pressure-overload. (A) SOD activity, (B) MDA production and (C) NADPH activity were assessed in each group $(n=15)$. mRNA levels of (D) NOX2 and (E) NOX4 were also detected in each group. Protein levels of (F) NOX2 and NOX4 and (G) quantitative analysis are presented for each group. $(\mathrm{H})$ Immunohistochemistry staining for $4-\mathrm{HNE}$ and (I) subsequent quantification was performed. ${ }^{*} \mathrm{P}<0.05$ vs. the vehicle + sham group. ${ }^{\text {P }}<0.05$ vs. the vehicle + AB group. 4-HNE, 4-hydroxynonenal; SOD, superoxide dismutase; MDA, malondialdehyde; NOX2, NADPH oxidase 2; NOX4, NADPH oxidase 4; CA, carnosic acid; AB, aortic banding.

ated pressure overload-induced cardiac remodelling by inhibiting oxidative stress. SOD activity was increased by $\mathrm{CA}$ treatment in the pressure overload-induced hearts of mice compared with the vehicle + AB group (Fig. 4A). However, MDA production and NADPH activity induced by $A B$ surgery were significantly decreased by $C A$ treatment when compared with the vehicle $+A B$ group (Fig. $4 \mathrm{~B}$ and $\mathrm{C}$ ). The present study also investigated the expression of NOX induced by pressure overload and identified that the expression of NOX2 and NOX4 were increased at both mRNA (Fig. 4D and E) and protein levels (Fig. 4F and G) compared with the vehicle + sham and $\mathrm{CA}+$ sham groups. Additionally, CA treatment significantly reduced the expression of NOX2 and NOX4 at the mRNA and protein levels. Furthermore, immunohistochemical staining indicated that the expression of 4-HNE, a product of oxidative stress, was increased following AB surgery and reversed by CA treatment (Fig. 4H and I). The present results suggested that $\mathrm{CA}$ 


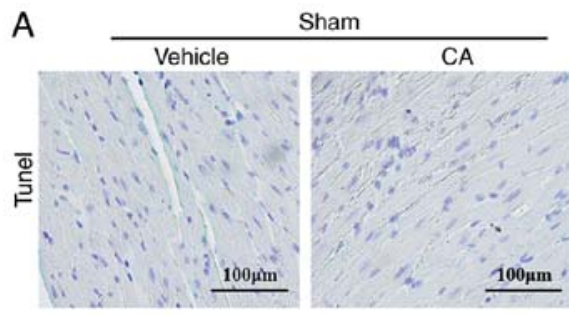

C

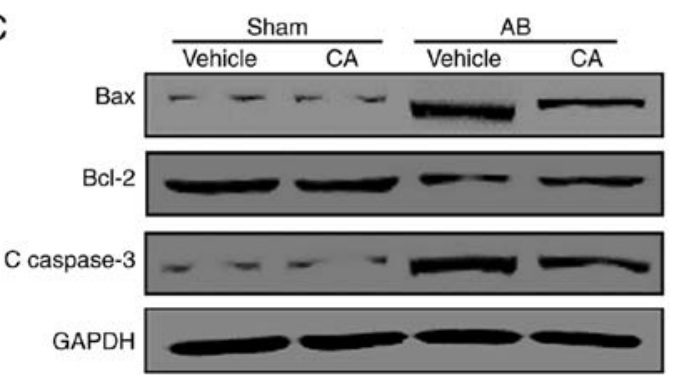

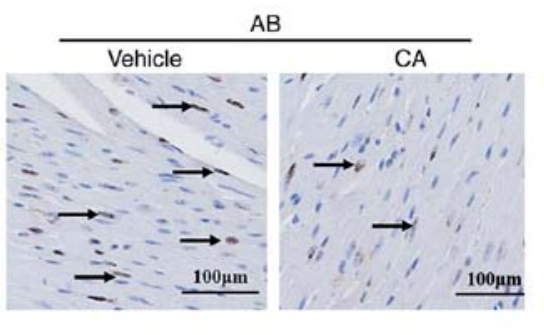

B

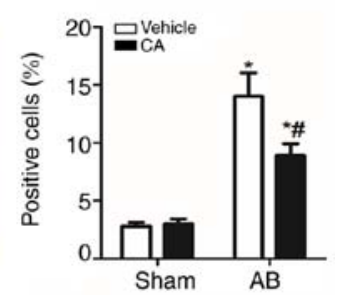

Figure 5. CA inhibited apoptosis in mice induced by pressure-overload. (A) TUNEL staining (the arrows indicated the apoptotic cells) and (B) quantitative analysis of apoptotic cells in each group ( $\mathrm{n}=15)$. Scale bar, $100 \mu \mathrm{m}$. (C) Protein levels of $\mathrm{Bcl}-2$, Bax and C-caspase3 and (D) quantitative analysis are presented for each group. ${ }^{*} \mathrm{P}<0.05$ vs. the vehicle + sham group. ${ }^{"} \mathrm{P}<0.05$ vs. the vehicle $+\mathrm{AB}$ group. $\mathrm{CA}$, carnosic acid; $\mathrm{AB}$, aortic banding.
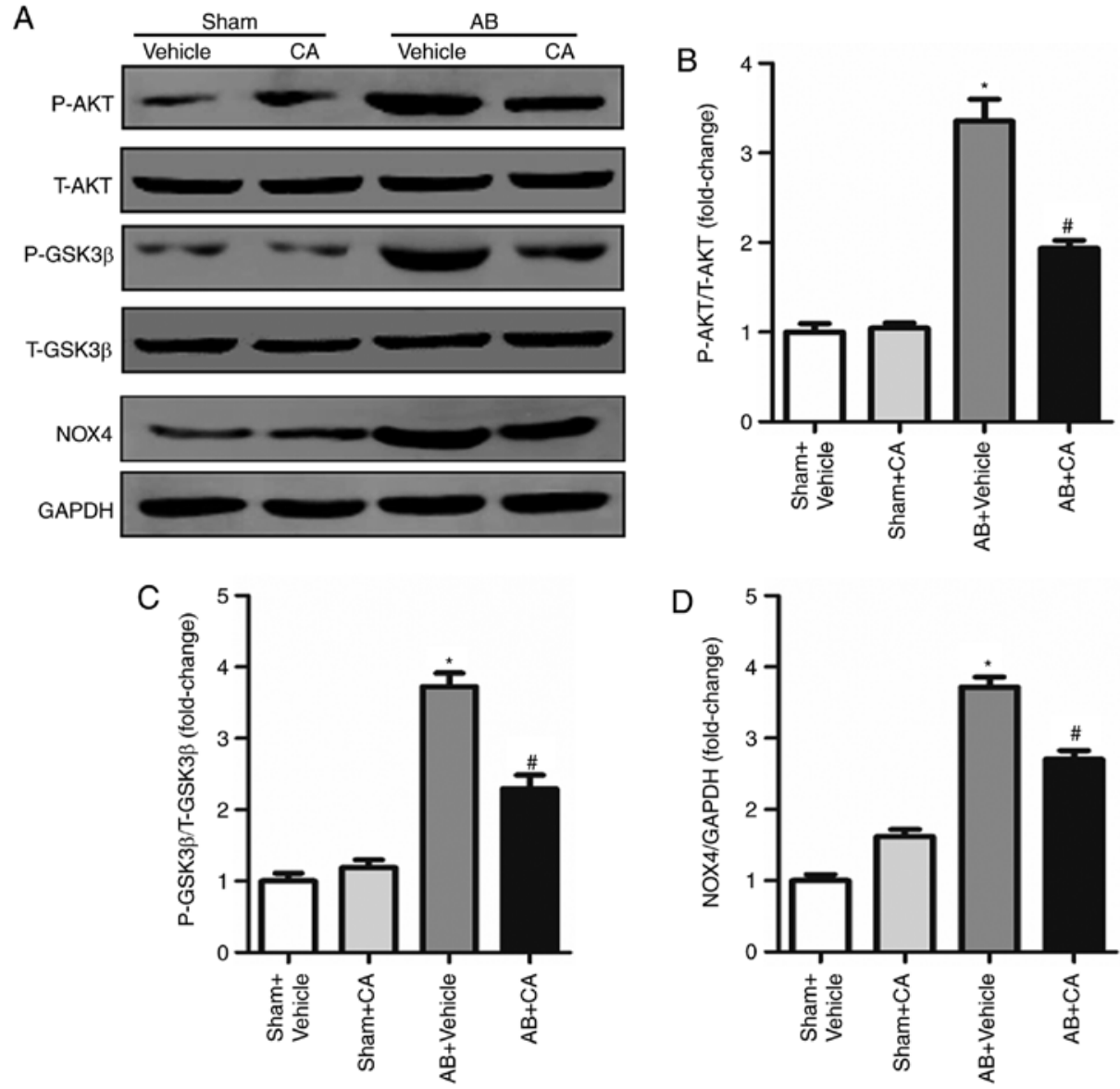

Figure 6. CA protected against cardiac remodelling by regulating the AKT/GSK3 $\beta /$ NOX4 signalling pathway. (A) Expression of p-AKT, p-GSK3 $\beta$ and NOX4 were determined in each group $(n=15)$. Quantification analysis of (B) $p-A K T / t-A K T,(C) p-G S K 3 \beta / t-G S K 3 \beta$ and $(D)$ NOX4 protein. ${ }^{*} \mathrm{P}<0.05$ vs. the vehicle + sham group. ${ }^{\#} \mathrm{P}<0.05$ vs. the vehicle $+\mathrm{AB}$ group. $\mathrm{CA}$, carnosic acid; $\mathrm{AB}$, aortic banding; GSK3$\beta$, glycogen synthase kinase $3 \beta$; $\mathrm{p}$-, phosphorylated; t-, total; NOX4, NADPH oxidase 4.

may suppress cardiac fibrosis by inhibiting NADPH oxidase mediated oxidative stress.
CA inhibits apoptosis in mice induced by pressure overload. Previous studies have demonstrated that oxidative stress can 


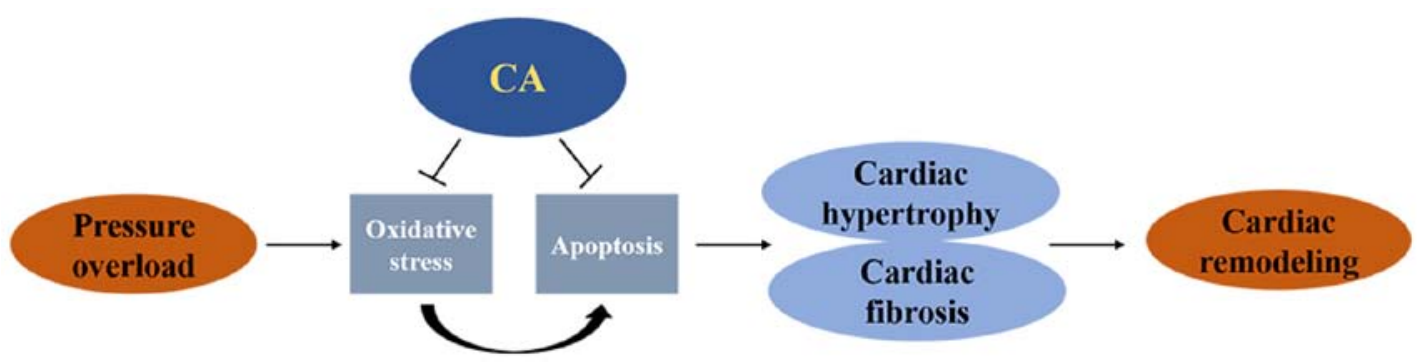

Figure 7. CA protected against pressure overload-induced cardiac remodelling by inhibiting oxidative stress and apoptosis. Oxidative stress also directly mediated apoptosis. CA, carnosic acid.

activate apoptosis via different pathways and cause cardiac injury $(14,26)$. CA has the ability to inhibit oxidative stress and apoptosis (11). Therefore, the present study performed TUNEL staining and detected the expression of apoptosis-associated proteins to evaluate the cardioprotective effect of CA following pressure overload in mice. The present results identified that the apoptosis ratio was increased in the vehicle $+\mathrm{AB}$ group compared with the vehicle + sham and $\mathrm{CA}+$ sham groups, and decreased after CA treatment (Fig. 5A and B). Furthermore, the expression of certain pro-apoptotic proteins, including Bax and $\mathrm{C}$-caspase- 3 were increased in the vehicle $+\mathrm{AB}$ group compared with the vehicle + sham and $\mathrm{CA}+$ sham groups, and decreased after CA treatment (Fig. 5C and D). The expression of the anti-apoptotic protein, Bcl-2, decreased in the vehicle $+\mathrm{AB}$ group compared with the vehicle + sham and $\mathrm{CA}+$ sham groups, and increased after CA treatment (Fig. 5C and D). However, there were no differences between the vehicle + sham group and the CA + sham group. Therefore, the present results suggested that $\mathrm{CA}$ inhibited pressure overload induced-cardiomyocyte apoptosis.

CA protects against cardiac remodelling by regulating the AKT/GSK3/NOX4 signalling pathway. To assess the underlying mechanism of the effect of CA acting on cardiac remodelling, the present study investigated the AKT/GSK3//NOX4 signalling pathway. The present results suggested that $\mathrm{CA}$ treatment significantly reduced the expression of p-AKT, p-GSK3 $\beta$ and NOX4 induced by AB (Fig. 6A-D). The present results indicated that CA may exert its protective effect against cardiac remodelling by suppressing the AKT/GSK3 $3 / \mathrm{NOX} 4$ signalling pathway.

\section{Discussion}

The present study performed $\mathrm{AB}$ surgery to establish a mouse cardiac remodelling model. The present results suggested CA treatment not only protected against pressure overload-induced cardiac hypertrophy, but also attenuated cardiac fibrosis. Furthermore, CA treatment inhibited oxidative stress and apoptosis following AB surgery. Taken together, the present results suggested that $\mathrm{CA}$ may be a potential candidate for cardiac remodelling induced by pressure-overload (Fig. 7).

Heart failure is a clinical syndrome of cardiac circulation disorder caused by ventricular systolic or diastolic insufficiency and has become a serious social and public health problem (27). Pathological cardiac remodelling is induced by various stimuli, including inflammation, biomechanical stress and pressure overload. In pressure overload, cardiomyocytes develop hypertrophy with a series of changes, such as abnormal gene transcription and protein synthesis and apoptosis. With the prolongation of stimulation, these changes result in increasing extracellular matrix and cardiac fibrosis (2). Cardiac fibrosis is the adaptive response of the heart to various forms of injury during which cardiac fibroblasts transform into myofibroblasts (2).

Previous studies have reported that oxidative stress is implicated in the pathophysiology of cardiac remodelling, which impairs heart pumping capacity and ultimately contributes to heart failure $(28,29)$. NOX is the main source of ROS that induces oxidative stress in the heart and NOX2 and NOX4 are primarily associated with the heart (30). Under pathological conditions, activated NOX2 reduces oxygen molecules into oxygen ions via NADPH, thus leading to heart injury (31). Liu et al (32), demonstrated that NOX2 promoted the synthesis of collagen I and III in neonatal rat cardiac fibroblasts, leading to cardiac fibrosis. Furthermore, NOX2 enhanced angiotensin II induced ROS generation and cardiomyocyte hypertrophy (33). NOX4 produces hydrogen peroxide via a disproportionation reaction with oxygen ions, thereby regulating ROS production (34). A previous study revealed that NOX4 upregulated transverse aortic constriction-induced cardiomyocyte hypertrophy and left ventricular dysfunction (35). A further study demonstrated that NOX4 contributed to angiotensin-II-induced adult mouse cardiac fibroblast proliferation and migration (36). The present results indicated that the production of MDA and the activities of SOD and NADPH were significantly increased following AB surgery. In addition, the present results identified that the mRNA and protein expression of NOX2 and NOX4 were significantly increased following $\mathrm{AB}$ surgery. As a lipid peroxide formed by the lipid peroxidation reaction between ROS and biomacromolecules, 4-HNE exerts a destructive effect on cardiac tissue by interfering with adducts formed by organelles such as mitochondria (37). In the present study, the expression of 4-HNE was significantly increased in the vehicle $+A B$ group. The present results indicated that the inhibition of oxidative stress may improve cardiac hypertrophy and fibrosis.

The accumulation of ROS components such as superoxide anions, hydroxyl free radicals and hydrogen peroxide, can damage the integrity and function of the cell membrane and lead to cell apoptosis (38). A previous study has suggested that increased ROS can induce cardiomyocyte apoptosis by activating certain apoptotic signals, including caspase-3 (39). Additionally, angiotensin II-mediated NADPH oxidase-induced ROS mediate cardiomyocyte apoptosis via the mitochondrial apoptotic pathway (26). The present results 
demonstrated that the number of TUNEL-positive cells was significantly increased upon pressure overload. Furthermore, the expression of certain pro-apoptotic proteins, including Bax and C-caspase-3, were increased, while the expression of the anti-apoptotic protein, Bcl-2, was decreased following $\mathrm{AB}$ surgery. The present results indicated that ROS-mediated oxidative stress serves a key role in cell apoptosis and that the inhibition of apoptosis may serve a protective role in the heart.

$\mathrm{CA}$ is the major component extracted from rosemary plants and has anti-cancer, anti-inflammatory and anti-obesity effects (40). A previous study demonstrated that CA suppressed oxidative stress by inhibiting the expression of NOX4 in transforming growth factor $\beta$-stimulated fibroblasts and unilateral ureteral obstruction-operated kidneys (41). In addition, CA alleviated bile duct ligation induced the expression of $\alpha$-SMA and collagen I in the liver and served an anti-fibrotic role in the livers of rats (42). Previous studies have indicated that CA serves an antioxidant role in different diseases, including arsenic-induced hepatotoxicity (10) and isoproterenol-induced myocardial stress (14). Furthermore, it has been demonstrated that CA attenuated amyloid- $\beta$ peptide-induced human neuroblastoma cell apoptosis (43) and isoproterenol-induced cardiomyocyte apoptosis (14). However, several studies have determined that CA induced apoptosis in various cancer models, possibly due to different doses and models affecting the pharmacological effects of CA $(44,45)$. The present results indicated that CA treatment inhibited pressure overload-induced cardiac hypertrophy and fibrosis, and reduced oxidative stress and apoptosis, as well as improving cardiac function.

AKT is a serine-threonine kinase that serves an important role in cardiac growth and metabolism (46). Activated AKT stimulates downstream GSK3 $\beta$ and participates in the pathophysiology of cardiac hypertrophy $(15,16)$. p-Akt increases the size of cardiac myocytes and promotes the development of heart failure (47). Furthermore, NOX4 serves an important role in the differentiation of myofibroblasts into different phenotypes $(48,49)$. A previous study indicated that CA alleviated AKT-mediated renal fibrosis by reducing the expression of NOX4 (17). The present results indicated that CA significantly decreased the expression of p-AKT, p-GSK $3 \beta$ and NOX4 induced by $\mathrm{AB}$. Therefore, the role of $\mathrm{CA}$ in cardiac remodelling may rely on the AKT/GSK3K3/NOX4 signalling pathway.

In conclusion, the present results indicated that CA significantly attenuated pressured overload-induced cardiac hypertrophy and fibrosis, and that the potential mechanism may be attributed to the inhibition of oxidative stress and apoptosis.

\section{Acknowledgements}

Not applicable.

\section{Funding}

No funding was received.

\section{Availability of data and materials}

The datasets used and/or analysed during the current study are available from the corresponding author on reasonable request.

\section{Authors' contributions}

YJW and FC conceived the present study and designed the experiments. HJX and JJC performed the experiments. YJW and FC wrote and revised the manuscript; XY, JX and JW analysed experimental results. All authors read and approved the final manuscript

\section{Ethics approval and consent to participate}

All animal care and experiments were based on the Guidelines for the Care and Use of Laboratory Animals published by the United States National Institutes of Health (NIH Publication, revised 2011) and were approved by the Animal Care and Use Committee of Wuhan University.

\section{Patient consent for publication}

Not applicable.

\section{Competing interests}

The authors declare that they have no competing interests.

\section{References}

1. Jaiswal A, Nguyen VQ, Carry BJ and le Jemtel TH: Pharmacologic and endovascular reversal of left ventricular remodeling. J Card Fail 22: 829-839, 2016.

2. Wu QQ, Xiao Y, Yuan Y, Ma ZG, Liao HH, Liu C, Zhu JX, Yang Z, Deng W and Tang QZ: Mechanisms contributing to cardiac remodelling. Clin Sci (Lond) 131: 2319-2345, 2017.

3. Wang H, Sun X, Lin MS, Ferrario CM, Van Remmen H and Groban L: G protein-coupled estrogen receptor (GPER) deficiency induces cardiac remodeling through oxidative stress. Transl Res 199: 39-51, 2018.

4. Al-Darraji A,Haydar D, Chelvarajan L, Tripathi H,Levitan B, GaoE, Venditto VJ, Gensel JC, Feola DJ and Abdel-Latif A: Azithromycin therapy reduces cardiac inflammation and mitigates adverse cardiac remodeling after myocardial infarction: Potential therapeutic targets in ischemic heart disease. PLoS One 13: e0200474, 2018.

5. Eid RA, Alkhateeb MA, Al-Shraim M, Eleawa SM, Shatoor AS, El-Kott AF, Zaki MSA, Shatoor KA, Bin-Jaliah I and Al-Hashem FH: Ghrelin prevents cardiac cell apoptosis during cardiac remodelling post experimentally induced myocardial infarction in rats via activation of Raf-MEK $1 / 2-$ ERK $1 / 2$ signalling. Arch Physiol Biochem 125: 93-103, 2019.

6. Sciarretta S, Yee D, Nagarajan N, Bianchi F, Saito T, Valenti V, Tong M,DelReDP, VecchioneC,Schirone L, etal: Trehalose-Induced Activation of Autophagy Improves Cardiac Remodeling After Myocardial Infarction. J Am Coll Cardiol 71: 1999-2010, 2018.

7. Zhang M, Perino A, Ghigo A, Hirsch E and Shah AM: NADPH oxidases in heart failure: Poachers or gamekeepers? Antioxid Redox Signal 18: 1024-1041, 2013.

8. Zhao QD, Viswanadhapalli S, Williams P, Shi Q, Tan C, Yi X, Bhandari B and Abboud HE: NADPH oxidase 4 induces cardiac fibrosis and hypertrophy through activating Akt/mTOR and NFxB signaling pathways. Circulation 131: 643-655, 2015.

9. Zhang Y, Tocchetti CG, Krieg T and Moens AL: Oxidative and nitrosative stress in the maintenance of myocardial function. Free Radic Biol Med 53: 1531-1540, 2012.

10. Das S, Joardar S, Manna P, Dua TK, Bhattacharjee N, Khanra R, Bhowmick S, Kalita J, Saha A, Ray S, et al: Carnosic acid, a natural diterpene, attenuates arsenic-induced hepatotoxicity via reducing oxidative stress, MAPK activation, and apoptotic cell death pathway. Oxid Med Cell Longev 2018: 1421438, 2018.

11. Liu M, Zhou X, Zhou L, Liu Z, Yuan J, Cheng J, Zhao J, Wu L, $\mathrm{Li} \mathrm{H}$, Qiu H, et al: Carnosic acid inhibits inflammation response and joint destruction on osteoclasts, fibroblast-like synoviocytes, and collagen-induced arthritis rats. J Cell Physiol 233: 6291-6303, 2018. 
12. Manoharan S, Vasanthaselvan M, Silvan S, Baskaran N, Kumar Singh A and Vinoth Kumar V: Carnosic acid: A potent chemopreventive agent against oral carcinogenesis. Chem Biol Interact 188: 616-622, 2010.

13. Li H, Sun JJ, Chen GY, Wang WW, Xie ZT, Tang GF and Wei SD: Carnosic acid nanoparticles suppress liver ischemia/reperfusion injury by inhibition of ROS, Caspases and NF- $x \mathrm{~B}$ signaling pathway in mice. Biomed Pharmacother 82: 237-246, 2016.

14. Sahu BD, Putcha UK, Kuncha M, Rachamalla SS and Sistla R: Carnosic acid promotes myocardial antioxidant response and prevents isoproterenol-induced myocardial oxidative stress and apoptosis in mice. Mol Cell Biochem 394: 163-176, 2014.

15. Bénard L, Oh JG, Cacheux M, Lee A, Nonnenmacher M, Matasic DS, Kohlbrenner E, Kho C, Pavoine C, Hajjar RJ and Hulot JS: Cardiac stim1 silencing impairs adaptive hypertrophy and promotes heart failure through inactivation of mTORC2/Akt signaling. Circulation 133: 1458-1471, 2016.

16. Li J, Kritzer MD, Michel JJ, Le A, Thakur H, Gayanilo M Passariello CL, Negro A, Danial JB, Oskouei B, et al: Anchored p90 ribosomal S6 kinase 3 is required for cardiac myocyte hypertrophy. Circ Res 112: 128-139, 2013.

17. Jung KJ, Min KJ, Park JW, Park KM and Kwon TK: Carnosic acid attenuates unilateral ureteral obstruction-induced kidney fibrosis via inhibition of Akt-mediated Nox4 expression. Free Radic Biol Med 97: 50-57, 2016.

18. National Research Council (US) Committee for the Update of the Guide for the Care and Use of Laboratory Animals: Guide for the Care and Use of Laboratory Animals. National Academies Press, Washington, DC, 2011

19. Jiang DS, Liu Y, Zhou H, Zhang Y, Zhang XD, Zhang XF, Chen K, Gao L, Peng J, Gong H, et al: Interferon regulatory factor 7 functions as a novel negative regulator of pathological cardiac hypertrophy. Hypertension 63: 713-722, 2014.

20. Ma ZG, Yuan YP, Xu SC, Wei WY, Xu CR, Zhang X, Wu QQ, Liao HH, Ni J and Tang QZ: CTRP3 attenuates cardiac dysfunction, inflammation, oxidative stress and cell death in diabetic cardiomyopathy in rats. Diabetologia 60: 1126-1137, 2017.

21. Gao S, Ho D, Vatner DE and Vatner SF: Echocardiography in mice. Curr Protoc Mouse Biol 1: 71-83, 2011.

22. Troy BL, Pombo J and Rackley CE: Measurement of left ventricular wall thickness and mass by echocardiography. Circulation 45: 602-611, 1972.

23. Wu QQ, Xiao Y, Jiang XH, Yuan Y, Yang Z, Chang W, Bian ZY and Tang QZ: Evodiamine attenuates TGF- $\beta 1$-induced fibroblast activation and endothelial to mesenchymal transition. Mol Cell Biochem 430: 81-90, 2017.

24. Zhang N, Wei WY, Yang Z, Che Y, Jin YG, Liao HH, Wang SS, Deng $\mathrm{W}$ and Tang QZ: Nobiletin, a polymethoxy flavonoid, protects against cardiac hypertrophy induced by pressure-overload via inhibition of NAPDH oxidases and endoplasmic reticulum stress. Cell Physiol Biochem 42: 1313-1325, 2017.

25. Ibarra-Lara L, Hong E, Soria-Castro E, Torres-Narváez JC, Pérez-Severiano F, Del Valle-Mondragón L, Cervantes-Pérez LG Ramírez-Ortega $M$, Pastelín-Hernández GS and Sánchez-Mendoza A: Clofibrate PPAR $\alpha$ activation reduces oxidative stress and improves ultrastructure and ventricular hemodynamics in no-flow myocardial ischemia. J Cardiovasc Pharmacol 60: 323-334, 2012.

26. Qin F, Patel R, Yan C and Liu W: NADPH oxidase is involved in angiotensin II-induced apoptosis in $\mathrm{H} 9 \mathrm{C} 2$ cardiac muscle cells: Effects of apocynin. Free Radic Biol Med 40: 236-246, 2006.

27. Yang CJ, Yang J, Fan ZX, Zhang J, Liu XW and Yang J: Diagnostic value of soluble ST2 in heart failure: A meta-analysis. Bachu Med J 1: 52-59, 2018.

28. Liu JJ,Lu Y,Ping NN,Li X,Lin YX and Li CF: Apocynin ameliorates pressure overload-induced cardiac remodeling by inhibiting oxidative stress and apoptosis. Physiol Res 66: 741-752, 2017.

29. Li W, Wu X, Li M, Wang Z, Li B, Qu X and Chen S: Cardamonin alleviates pressure overload-induced cardiac remodeling and dysfunction through inhibition of oxidative stress. J Cardiovasc Pharmacol 68: 441-451, 2016.

30. Bryk D, Olejarz W and Zapolska-Downar D: The role of oxidative stress and NADPH oxidase in the pathogenesis of atherosclerosis. Postepy Hig Med Dosw 71: 57-68, 2017.

31. Cangemi R, Calvieri C, Bucci T, Carnevale R, Casciaro M, Rossi E, Calabrese CM, Taliani G, Grieco S, Falcone M, et al; SIXTUS study group: Is NOX2 upregulation implicated in myocardial injury in patients with pneumonia? Antioxid Redox Signal 20: 2949-2954, 2014.
32. Liu Y and Zhang J: Nox 2 contributes to cardiac fibrosis in diabetic cardiomyopathy in a transforming growth factor- $\beta$ dependent manner. Int J Clin Exp Pathol 8: 10908-10914, 2015.

33. Hingtgen SD, Tian X, Yang J, Dunlay SM, Peek AS, Wu Y, Sharma RV, Engelhardt JF and Davisson RL: Nox2-containing NADPH oxidase and Akt activation play a key role in angiotensin II-induced cardiomyocyte hypertrophy. Physiol Genomics 26: 180-191, 2006

34. Siu KL, Lotz C, Ping $P$ and Cai H: Netrin-1 abrogates ischemia/reperfusion-induced cardiac mitochondrial dysfunction via nitric oxide-dependent attenuation of NOX4 activation and recoupling of NOS. J Mol Cell Cardiol 78: 174-185, 2015.

35. Matsushima S, Kuroda J, Zhai P, Liu T, Ikeda S, Nagarajan N, Oka S, Yokota T, Kinugawa S, Hsu CP, et al: Tyrosine kinase FYN negatively regulates NOX4 in cardiac remodeling. J Clin Invest 126: 3403-3416, 2016.

36. Somanna NK, Valente AJ, Krenz M, Fay WP, Delafontaine P and Chandrasekar B: The Nox1/4 Dual inhibitor GKT137831 or Nox4 knockdown inhibits angiotensin-II-induced adult mouse cardiac fibroblast proliferation and migration. AT1 physically associates with Nox4. J Cell Physiol 231: 1130-1141, 2016.

37. Deshpande M, Mali VR,Pan G, Xu J, Yang XP, Thandavarayan RA and Palaniyandi SS: Increased 4-hydroxy-2-nonenal-induced proteasome dysfunction is correlated with cardiac damage in streptozotocin-injected rats with isoproterenol infusion. Cell Biochem Funct 34: 334-342, 2016.

38. Sinha K, Das J, Pal PB and Sil PC: Oxidative stress: The mitochondria-dependent and mitochondria-independent pathways of apoptosis. Arch Toxicol 87: 1157-1180, 2013.

39. Kumar D and Jugdutt BI: Apoptosis and oxidants in the heart. J Lab Clin Med 142: 288-297, 2003.

40. Sahu BD, Rentam KK, Putcha UK, Kuncha M, Vegi GM and Sistla R: Carnosic acid attenuates renal injury in an experimental model of rat cisplatin-induced nephrotoxicity. Food Chem Toxicol 49: 3090-3097, 2011.

41. Jung KJ, Min KJ, Park JW, Park KM and Kwon TK: Carnosic acid attenuates unilateral ureteral obstruction-induced kidney fibrosis via inhibition of Akt-mediated Nox4 expression. Free Radic Biol Med 97: 50-57, 2016.

42. Zhang S, Wang Z, Zhu J, Xu T, Zhao Y, Zhao H, Tang F, Li Z, Zhou J, Gao D, et al: Carnosic acid alleviates BDL-induced liver fibrosis through miR-29b-3p-mediated inhibition of the high-mobility group Box 1/Toll-Like receptor 4 signaling pathway in rats. Front Pharmacol 8: 976, 2018.

43. Meng P, Yoshida H, Tanji K, Matsumiya T, Xing F, Hayakari R, Wang L, Tsuruga K, Tanaka H, Mimura J, et al: Carnosic acid attenuates apoptosis induced by amyloid- $\beta 1-42$ or $1-43$ in SH-SY5Y human neuroblastoma cells. Neurosci Res 94: 1-9, 2015.

44. Shi B, Wang LF, Meng WS, Chen L and Meng ZL: Carnosic acid and fisetin combination therapy enhances inhibition of lung cancer through apoptosis induction. Int J Oncol 50: 2123-2135, 2017.

45. Han NN, Zhou Q, Huang Q and Liu KJ: Carnosic acid cooperates with tamoxifen to induce apoptosis associated with Caspase-3 activation in breast cancer cells in vitro and in vivo. Biomed Pharmacother 89: 827-837, 2017.

46. Abeyrathna P and Su Y: The critical role of Akt in cardiovascular function. Vascul Pharmacol 74: 38-48, 2015.

47. Chaanine AH and Hajjar RJ: AKT signalling in the failing heart. Eur J Heart Fail 13: 825-829, 2011.

48. Barnes JL and Gorin Y: Myofibroblast differentiation during fibrosis: Role of NAD(P)H oxidases. Kidney Int 79: 944-956, 2011.

49. Hecker L, Vittal R, Jones T, Jagirdar R, Luckhardt TR, Horowitz JC, Pennathur S, Martinez FJ and Thannickal VJ: NADPH oxidase-4 mediates myofibroblast activation and fibrogenic responses to lung injury. Nat Med 15: 1077-1081, 2009.

This work is licensed under a Creative Commons Attribution-NonCommercial-NoDerivatives 4.0 International (CC BY-NC-ND 4.0) License. 